\title{
SOLAHP: a fledgling organization rapidly taking flight
}

\section{William R. Macon ${ }^{1}$}

Published online: 31 August 2019

(C) Springer-Verlag GmbH Germany, part of Springer Nature 2019

The Latin American Society of Hematopathology (SOLAHP) is a "very young" organization whose stated reason for being is to "encourage the development of hematopathology in Latin America by transmitting the tools that improve diagnostic quality for therapeutic and prognostic purposes" (http:// www.solahp.org). One means by which SOLAHP accomplishes this goal is by organizing a meeting that offers an economically accessible opportunity for dissemination of high-level academic information (http://www.solahp.org).

As such, I had the opportunity to attend the Second Latin American Congress of Hematopathology, which was held May 23-25, 2019, in Bogotá, Colombia. Styled after the biennial European Association for Haematopathology (EAHP) meetings, it featured lectures by an internationally acclaimed faculty composed of Leticia Quintanilla-Fend (Tübingen, Germany), Birgitta Sander (Stockholm, Sweden), Philippe Gaulard (Créteil, France), German Ott (Stuttgart, Germany), Robert Hasserjian (Boston, MA, USA), and Julia Geyer (New York, NY, USA). Among the topics of worldwide interest they addressed were as follows: "Advances in follicular lymphomas" (Quintanilla-Fend), "What's new in mantle cell lymphoma: relevance of new mutations" (Sander), "The clear-cut definition of high-grade B-cell lymphomas" (Ott), "Molecular update in AITL and the relevance of TFH phenotype" (Gaulard), "The current approach in the diagnosis of myelodysplastic syndromes" (Hasserjian), and "Updates in the diagnosis of plasma cell neoplasms: an approach for daily pathology practice" (Geyer). Gaulard delivered the keynote address: "Lymphoma classification: where do we stand?" in which he took the audience of greater than 100 participants through a brief history of lymphoma classification (Rappaport to Kiel [and Lukes-Collins] to REAL and to the WHO) to issues encountered currently in the evolution of lymphoma classification, such as advances in molecular knowledge,

William R. Macon

Macon.William@mayo.edu

1 Mayo Clinic, Rochester, MN, USA therapeutic implications, and problems created by "in situ" lesions.

Workshop case presentations were interspersed throughout the meeting and were typically related to the topic of the faculty lectures they followed. These workshop cases, as well as the scientific papers presented by Latin American pathologists and hematopathologists, were highly informative about some of the hematopathological issues encountered specifically in Latin American countries and accomplished another goal of SOLAHP: "exchange and dissemination of knowledge related to hematopathology by establishing links between Latin America and the rest of the world" (http://www.solahp.org).

The organizing committee, Carmen Lome Maldonado (Mexico City, Mexico), Anahí Vijnovich Barón (Buenos Aries, Argentina), and Rocío Orduz (Bogotá, Colombia), are to be commended for putting together a well-organized and highly interesting academic meeting in a casual and friendly atmosphere. Of particular note was the ease by which realtime Spanish-English translations were made via headphones for all participants. That did produce a few Abbott and Costello-like moments for faculty members who spoke their lectures in English, received questions from the audience in Spanish that were translated to English through their headphones, and replied in English while immediately hearing their answers in Spanish via the headphones if they had not removed them first.

Congratulations SOLAHP and Bogotá for a meeting well done.

Based on my personal experience and the exceptional "bang for the buck" I received: I hope to see you in Brazil for the next meeting of SOLAHP, 2021.

William R. Macon, M.D.

Editor-in-Chief

Journal of Hematopathology
Publisher's note Springer Nature remains neutral with regard to jurisdictional claims in published maps and institutional affiliations. 